\title{
PENGARUH BERBAGAI JENIS FUNGISIDA TERHADAP PERKEMBANGAN JAMUR Fusarium Oxysporum
}

\section{The Effect of Fungicides on Fusarium oxysporum Growth}

\author{
Dadi Nurdiana ${ }^{1}$, Rahmi Fatimah ${ }^{2}$ \\ 1,2Program Studi Agroteknologi Fakultas Pertanian Universitas \\ Garut \\ E-mail : dadi_nurdiana@faperta.uniga.ac.id
}

\begin{abstract}
Abstrak
Penelitian ini dilakukan untuk mempelajari pengaruh dari berbagai jenis fungisida alami terhadap resiko fusarium penyakit layu (Fusarium oxysporum) in vitro. Percobaan dilakukan di Laboratorium Pertanian, Fakultas Pertanian Universitas Garut September-Oktober 2015. Perlakuan sebanyak 16 yang diulang sebanyak dua kali yang disusun dalam Rancangan Acak Lengkap (RAL). Semua data yang diamati dianalisis dengan uji scott knott. Perlakuannya yaitu: $\mathrm{F} 0=$ (Tanpa fungisida), $\mathrm{F} 1=$ Chitosan 1\%, F2 = Chitosan 2\%, F3 = Ekstrak Bayam duri 5\%, F4 = Ekstrak Bayam duri 10\%, F5 = Ekstrak Bawang putih 5\%, F6 $=$ Ekstrak Bawang putih 10\%, F7 = Ekstrak Jawer kotok 5\%, $\mathrm{F} 8=$ Ekstrak Jawer kotok 10\%, F9 = Ekstrak kangkung 5\%, F10 $=$ Ekstrak kangkung 10\%, F11 = Ekstrak Sirih 5\%, F12 = Ekstrak Sirih 10\%, F13 = Ekstrak serai wangi 5\%, F14 = Ekstrak wangi $10 \%, F 15$ = fungisida sintetis $3 \mathrm{~g} /$ /iter. Hasil menunjukkan bahwa ekstrak bawang putih dengan konsentrasi 10\% (F6) memberi efek terbaik pada penghambatanpertumbuhan hifa $F$. oxysporumyang ditunjukkan nilai terendah dalam panjang hifa dan diameter penghambatan.
\end{abstract}

Kata kunci: Fungisida alami, Penyakit layu Fusarium, In vitro

\begin{abstract}
The experiment was conducted to study the effect of different types of natural fungicide againts fusarium wilt disease (Fusarium oxysporum) In Vitro. The experiment conducted in Agricultural Laboratories, Faculty of Agriculture University of Garut from September to October 2015. The 16 treatments that replicated two times were arranged in Completely Randomized
\end{abstract}


Design (CRD). All observed data was analyzed with scott knott test. The treatments were namely: $F O=$ without natural Fungicide, $F 1=$ Chitosan 1\%, F2= Chitosan 2\%, F3= spiny pigweed (Amaranthus spinosus) $5 \%, F 4=$ spiny pigweed ( $A$. spinonus) $10 \%$, F5 $=$ Garlic (Allium sativum) $5 \%, F 6=$ Garlic (A. sativum) $10 \%, F 7=$ common coleus (Coleus blumei benth) $5 \%, F 8=$ common coleus (C. blumei benth) $10 \%$, F9= Water spinach (Ipomea aquatica) 5\%, F10 = Water spinach (I. aquatica) 10\%, $F 11=$ Betel $($ Piper betle L) 5\%, F12=Betel ( $P$. betle L) 10\%, F13 = Citronella (Cymbopogon nardus L.) 5\%, F14= Citronella (C. nardus L.) $10 \%, F 15=$ Synthetic fungicide containing active ingredient mankozeb $3 \mathrm{~g} /$ liter. The results showed: The garlic extract with concentration of $10 \%$ (F6) gave the best effect on the inhibition ofthe growth of $F$. oxysporum hyphae, it showed the lowest value in the hyphae length and diameter of inhibition.

Keywords : Natural fungicide, Fusarium wilt disease, In Vitro

\section{PENDAHULUAN}

Tomat termasuk komoditi hortikultura utama di Indonesia. Pada periode 1990-2013, produksi tomat Indonesia meningkat dengan dengan rata-rata pertumbuhan sebesar $6,27 \%$ per tahun. Sedangkan perkembangan konsumsi total tomat yang merupakan total konsumsi dari tomat sayur dan tomat buah cenderung berfluktuatif. Konsumsi tomat sayur tahun 2002 sebesar $\quad 1,54$ $\mathrm{kg} / \mathrm{kapita} / \mathrm{tahun}$ dan pada tahun 2013 konsumsinya meningkat menjadi 1,72 $\mathrm{kg} / \mathrm{kapita/tahun.} \mathrm{Konsumsi}$ tomat sayur tertinggi dicapai pada tahun 2008 yaitu sebesar 2,23 $\mathrm{kg} / \mathrm{kapita} / \mathrm{tahun}$.
Perkembangan konsumsi tomat buah selama periode 2002-2013 cenderung datar dan tidak terjadi banyak peningkatan. Tahun 2002 konsumsi tomat buah sebesar $\quad 0,02$ $\mathrm{kg} / \mathrm{kapita} /$ tahun dan meningkat menjadi 0,05 $\mathrm{kg} / \mathrm{kapita} /$ tahun pada tahun 2013 dengan rata-rata pertumbuhan 27,78\% per tahun. Konsumsi tomat buah tertinggi dicapai pada tahun 2011 yaitu sebesar 0,06 $\mathrm{kg} / \mathrm{kapita} / \mathrm{tahun}$. (Pusat Data dan Sistem Informasi Pertanian Sekretariat Jenderal Kementerian Pertanian, 2014). Adanya serangan penyakit seperti serangan jamur Fusarium oxyxporum dapat menurunkan produktivitas dan merugikan 
petani untuk itu perlu dilakukan pengendalian efektif namun tidak merugikan lingkungan. Pengendalian yang aman dan ramah lingkungan bisa dilakukan dengan pemanfaatan bahan alami dari tanaman yang mempunyai bahan aktif yang dapat menghambat pertumbuhan bakteri dan jamur. Tanaman yang dapat digunakan untuk fungisida alami di antaranya: bawang putih, bayam, jawer kotok, kangkung, sirih dan sereh wangi.

\begin{tabular}{lrr}
\multicolumn{2}{c}{ Tanaman-tanaman } \\
tersebut & mempunyai \\
kandungan & metabolit \\
sekunder & yang & dapat
\end{tabular} menghambat pertumbuhan. Seperti kandungan alisin pada bawang putih bermanfaat sebagai bakterisida dan fungisida yang dapat menghambat perkembangan cendawan maupun mikroba lainnya, selain bawang putih, jawer kotok juga dapat dimanfaatkan sebagai fungisida nabati, karena memiliki beberapa jenis metabolit sekunder yang bersifat anti biotik, seperti tannin, saponin, polifenol dan trieterpenoid. Akar bayam duri mengandung aspinasterol dan saponin sedangkan bagian pupus tumbuhan diketahui mengandung sterol, $\mathrm{N}$ - alkana, asam lemak, alkohol bebas, falvonoid, dan hydrocianc acid. Efek kasar tumbuhan memperlihatkan efek antifungi terhadap Cercospora cruenta penyebab penyakit bercak daun pada kacang hijau (Vigna radiata L.) Ekstrak sirih (Piperbetle L) yang mengandung senyawa aromatik seperti hidroksikavikol, kalvikol,dan betlepanol.

Senyawa-senyawa
aktif tersebut mampu
menekan pertumbuhan
jamur patogen dengan cara
mengganggu dinding sel
sehingga komponen penting
seperti protein keluar dari
sel dan sel jamur berangsung-angsur mati. Hasil penelitian menentukan bahwa pemberian ekstrak air daun serai wangi dapat menekan pertumbuhan dan serangan jamur pada tanaman mentimun. Semakin tinggi konsentrasi maka semakin tinggi efektivitas penekanan persentase daun terserang $85,8 \%$ dan intensitas serangan $\quad 92,87 \%$ sedangkan untuk peningkatan hasil adalah $6 \%$ dengan efektivitas peningkatan hasil $178,96 \%$. Bahan alternatif lain yang dapat digunakan untuk mengendalikan jamur $F$. oxysporum adalah menggunakan chitosan, 
karena chitosan dapat menyebabkan perubahan fisiologis pada tanaman sehingga tanaman terhindar dari cendawan fatogen yang masuk melalui akar dan daun.

$\begin{array}{lr}\text { Penelitian } & \text { ini } \\ \text { mencoba } & \text { mengkaji } \\ \text { seberapa besar } & \text { ekstrak } \\ \text { fungisida alami } & \text { dapat } \\ \text { menghambat pertumbuhan } & \text { jamur dan menentukan jenis } \\ \text { fungisida alami yang efektif } \\ \text { dan aman r untuk } \\ \text { mengendalikan jamur } \\ \text { Fusarium oxysporum. Dari } \\ \text { hasil penelitian ini } \\ \text { diharapkan dapat } \\ \text { memberikan informasi bagi } \\ \text { instansi pertanian dan dapat } \\ \text { dimanfaatkan oleh para } \\ \text { petani. }\end{array}$

\section{METODOLOGI}

Percobaan dilakukan di Laboratorium Pertanian Terpadu Fakultas Pertanian Universitas Garut. Waktu percobaan dilakukan pada bulan September sampai Oktober 2015.

$$
\text { Bahan }
$$

digunakan dalam percobaan ini meliputi sampel tanaman tomat yang terserang penyakit $F$. oxysporum, ekstrak fungisida alami dari tanaman jawer kotok, bawang putih, bayam duri, kangkung, sirih, dan serai wangi, fungisida berbahan aktif mankozeb, chitosan, klorok, aquades, etanol 96, asam cuka $2 \%$, dan media PDA (potato dextrose agar).

Alat yang digunakan pada percobaan ini yaitu tabung reaksi, rak tabung, oven, kertas saring, botol, label, cawan petri, baki, gunting, palstik, pipet, tisu, Autoclave, pinset, alat tulis, kamera, gelas ukur, mikroskop, labu Erlenmeyer, LAF (Laminar air flow), dan $\mathrm{pH}$ meter universal.

Rancangan

penelitian menggunakan Rancangan Acak Lengkap (RAL) dengan memberikan perlakuan beberapa jenis fungisida alami terhadap $F$. oxysporum isolat Garut untuk mengetahui diameter hambatan pertumbuhan jamur $F$. oxysporum yang terdidi dari 16 perlakuan, yang disusun pada tata letakpercobaan (lampiran 2), perlakuan tersebut yaitu : F0 $=$ Tanpa fungisida, $\mathrm{F} 1=$ Chitosan 1\%, F2 = Chitosan $2 \%, \mathrm{~F} 3=$ Ekstrak Bayam duri $5 \%, \quad \mathrm{~F} 4=$ Ekstrak Bayam duri 10\%, F5 = Ekstrak Bawang putih 5\%, F6 = Ekstrak Bawang putih $10 \%, F 7=$ Ekstrak Jawer kotok 5\%, F8 = Ekstrak Jawer kotok 10\%, F9 = Ekstrak kangkung 5\%, F10 $=$ Ekstrak kangkung 10\%, F11 = Ekstrak Sirih 5\%, F12 $=$ Ekstrak Sirih 10\%, F13 = Ekstrak serai wangi 5\%, F14 
$=$ Ekstrak wangi 10\%, F15 = fungisida sintetis $3 \mathrm{~g} /$ liter.

Populasi dan sampel yang digunakan adalah jamur $F$. oxysporum pada tanaman tomat yang diambil dari Kampung Malati Desa Padasuka Kecamatan Pasirwangi. Pengambilan sampel dilakukan dengan cara mencabut tanaman yang terserang dengan menggunakan tangan, kemudiaan dimasukan ke dalam plastik dan dibawa ke laboratorium untuk dilakukan kultur dan diisolasi.

Pengamatan utama

yaitu pengamatan yang parameternya dihitung atau diolah secara statistik. Pengamatan dilakukan setiap hari selama 7 hari setelah diinokulasi dengan mengukur diameter hambat jamur pada setiap perlakuan.

Pengamatan

penunjang adalah pengamatan yang datanya tidak dianalisis secara statistik, dalam penelitian ini pengamatan penunjang yang dilakukan adalah Pengamatan makroskopis dan mikroskopis dengan menggunakan mikroskop untuk melihat hifa $F$. oxysporum.
HASIL

PEMBAHASAN

DAN

Pada penelitian ini ekstrak bawang putih pada konsenstrasi $10 \%$ mempunyai daya hambat kuat dibandingkan dengan ekstrak fungisida yang lainya. Mustika dan Rahmat (1993) menyatakan bahwa konsentrasi suatu bahan yang berfungsi sebagai anti mikroba merupakan salah satu faktor besar kecilnya kemampuan dalam menghambat pertumbuhan mikroba yang diuji. Kerusakan yang ditimbulkan komponen anti mikroba dapat bersifat fungisidal (membunuh jamur) dan fungistatik (mencegah pertumbuhan vegetatif jamur). Menurut Martoredjo (1989) suatu komponen akan bersifat fungisidal atau fungistatik tergantung pada sifat senyawa aktifnya, konsentrasi, dan media yang digunakan.

$\begin{array}{rrr} & \text { Ekstrak } & \text { bawang } \\ \text { putih } & \text { dengan } & \text { konsentrasi } \\ 10 \% & \text { mampu } & \text { menekan }\end{array}$ pertumbuhan jamur $F$. oxysporum melalui penghambatan

pembentukan spora pada media PDA. Pada konsentrasi yang berbeda, jumlah spora yang terbentuk juga berbeda. Makin tinggi konsentrasi yang diberikan, semakin sedikit jumlahspora yang terbentuk, ini berarti 
bahwa esktrak bawang putih secara kuantitatifmampu menghambat pertumbuhan spora jamur $F$. oxysporum. Fungisida dapat bereaksi dengan gugusamino, karboksil, hidroksi, sulfihidril sehingga menyebabkan tidak aktifnya enzim tertentu, hal ini mengakibatkan tertutupnyaalur biokimia yang esensial pada jamur. Daya hambat ekstrak fungisida alami terhadap jamur $F$. oxysporum dilihat pada Tabel 1.

\section{Berdasarkan Tabel}

1. diketahui bahwa

perlakuan ekstrak fungisida alami memberikan pengaruh terhadap pertumbuhan jamur $F$. oxysporum. Perlakuan F6 berbeda nyata dibandingkan perlakuan F0 (Tanpa Fungisida ), F1, F2, F3, F4, F5, F7,F8, F9, F10, $F 11, F 12, F 13, F 14$ dan F15pada hari ke 1 sampai 7 setelah dinokulasi. Kandungan aliin dan alisin sebagai anti bakteri pada bawang putih diduga menghambat pertumbuhan dan merusak hifa. Beberapa fungisida menghambat proses pembentukan dinding sel yang diperlukan untuk memanjangkan hifa, percabangan, pembentukan spora, dan pembelahan sel. Grafik daya hambat fungisida dapat dilihat pada Gambar 1.

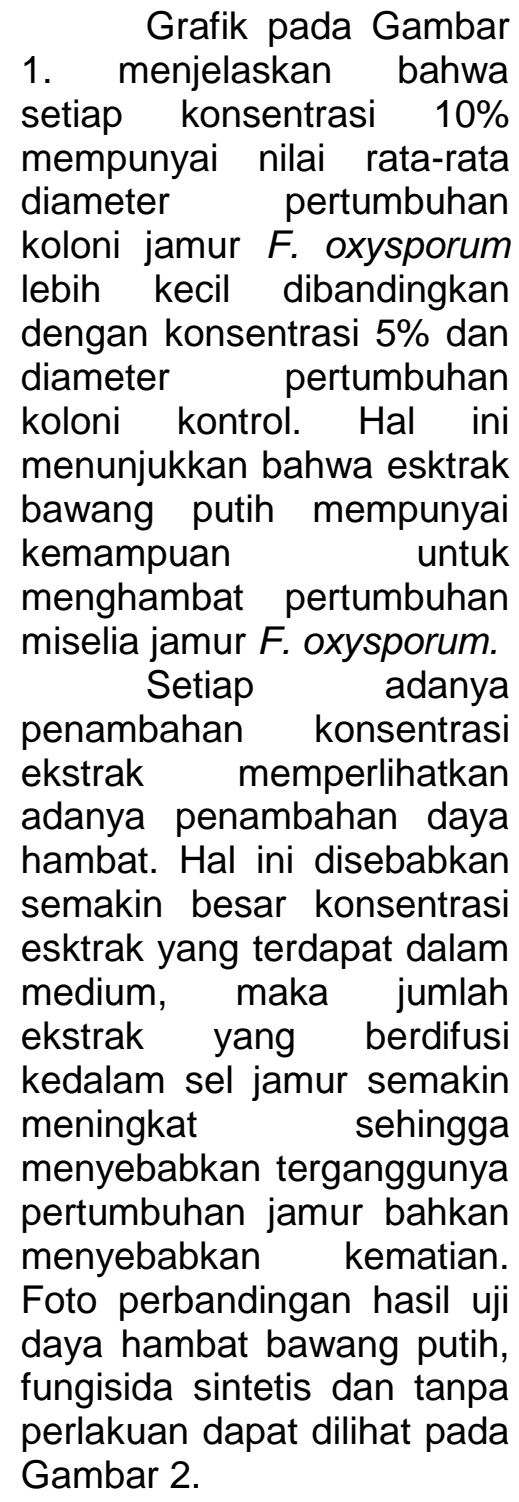

Grafik pada Gambar 1. menjelaskan bahwa setiap konsentrasi $10 \%$ mempunyai nilai rata-rata diameter pertumbuhan koloni jamur $F$. oxysporum lebih kecil dibandingkan dengan konsentrasi 5\% dan diameter pertumbuhan koloni kontrol. Hal ini menunjukkan bahwa esktrak bawang putih mempunyai kemampuan untuk menghambat pertumbuhan miselia jamur $F$. oxysporum. Setiap konsentrasi ekstrak memperlihatkan adanya penambahan daya hambat. Hal ini disebabkan semakin besar konsentrasi esktrak yang terdapat dalam medium, maka jumlah ekstrak yang berdifusi kedalam sel jamur semakin meningkat sehingga menyebabkan terganggunya pertumbuhan jamur bahkan menyebabkan kematian. daya hambat bawang putih, fungisida sintetis dan tanpa Gambar 2. 
Tabel 1. Diameter Pertumbuhan Jamur F.oxysporum

\begin{tabular}{|c|c|c|c|c|c|c|c|c|}
\hline \multirow{2}{*}{ No } & \multirow{2}{*}{ Perlakuan } & \multicolumn{7}{|c|}{ Pengamatan hari ke (mm) } \\
\cline { 3 - 9 } & & 1 & 2 & 3 & 4 & 5 & 6 & 7 \\
\hline 1 & $F_{0}$ & $9 \mathrm{~b}$ & $14 \mathrm{~b}$ & $17 \mathrm{~b}$ & $28 \mathrm{~b}$ & $32 \mathrm{~b}$ & $34 \mathrm{a}$ & $37 \mathrm{a}$ \\
\hline 2 & $\mathrm{~F}_{1}$ & $10 \mathrm{a}$ & $15,5 \mathrm{~b}$ & $24 \mathrm{a}$ & $30 \mathrm{~b}$ & $34 \mathrm{~b}$ & $37 \mathrm{a}$ & $40 \mathrm{a}$ \\
\hline 3 & $\mathrm{~F}_{2}$ & $10,5 \mathrm{a}$ & $20,5 \mathrm{a}$ & $28 \mathrm{a}$ & $36 \mathrm{a}$ & $45 \mathrm{a}$ & $49 \mathrm{a}$ & $53,5 \mathrm{a}$ \\
\hline 4 & $\mathrm{~F}_{3}$ & $8 \mathrm{~b}$ & $10,5 \mathrm{c}$ & $13 \mathrm{~b}$ & $15 \mathrm{c}$ & $17 \mathrm{c}$ & $18 \mathrm{~b}$ & $19 \mathrm{~b}$ \\
\hline 5 & $\mathrm{~F}_{4}$ & $8 \mathrm{~b}$ & $9 \mathrm{~d}$ & $11 \mathrm{~b}$ & $14 \mathrm{c}$ & $14 \mathrm{c}$ & $16 \mathrm{~b}$ & $16 \mathrm{~b}$ \\
\hline 6 & $\mathrm{~F}_{5}$ & $8 \mathrm{~b}$ & $11,5 \mathrm{c}$ & $13 \mathrm{~b}$ & $17 \mathrm{c}$ & $19 \mathrm{c}$ & $22 \mathrm{~b}$ & $25 \mathrm{~b}$ \\
\hline 7 & $\mathrm{~F}_{6}$ & $8,5 \mathrm{~b}$ & $9 \mathrm{~d}$ & $10 \mathrm{~b}$ & $11 \mathrm{c}$ & $12 \mathrm{c}$ & $13 \mathrm{~b}$ & $14 \mathrm{~b}$ \\
\hline 8 & $\mathrm{~F}_{7}$ & $8,5 \mathrm{~b}$ & $10,5 \mathrm{c}$ & $14,5 \mathrm{~b}$ & $26 \mathrm{~b}$ & $35 \mathrm{~b}$ & $39 \mathrm{a}$ & $42,5 \mathrm{a}$ \\
\hline 9 & $\mathrm{~F}_{8}$ & $8 \mathrm{~b}$ & $8 \mathrm{~d}$ & $12 \mathrm{~b}$ & $14 \mathrm{c}$ & $16,5 \mathrm{c}$ & $20 \mathrm{~b}$ & $23,5 \mathrm{~b}$ \\
\hline 10 & $\mathrm{~F}_{9}$ & $8 \mathrm{~b}$ & $9 \mathrm{~d}$ & $13 \mathrm{~b}$ & $14 \mathrm{c}$ & $17 \mathrm{c}$ & $20 \mathrm{~b}$ & $23 \mathrm{~b}$ \\
\hline 11 & $\mathrm{~F}_{10}$ & $8 \mathrm{~b}$ & $8,5 \mathrm{~d}$ & $10 \mathrm{~b}$ & $13 \mathrm{c}$ & $16 \mathrm{c}$ & $18 \mathrm{~b}$ & $19 \mathrm{~b}$ \\
\hline 12 & $\mathrm{~F}_{11}$ & $8,5 \mathrm{~b}$ & $10 \mathrm{c}$ & $11 \mathrm{~b}$ & $14 \mathrm{c}$ & $16 \mathrm{c}$ & $19 \mathrm{~b}$ & $21 \mathrm{~b}$ \\
\hline 13 & $\mathrm{~F}_{12}$ & $8 \mathrm{~b}$ & $8 \mathrm{~d}$ & $9 \mathrm{~b}$ & $10 \mathrm{c}$ & $12,5 \mathrm{c}$ & $12,5 \mathrm{~b}$ & $15,5 \mathrm{~b}$ \\
\hline 14 & $\mathrm{~F}_{13}$ & $9 \mathrm{~b}$ & $12 \mathrm{c}$ & $13 \mathrm{~b}$ & $16 \mathrm{c}$ & $17 \mathrm{c}$ & $19 \mathrm{~b}$ & $21 \mathrm{~b}$ \\
\hline 15 & $\mathrm{~F}_{14}$ & $8,5 \mathrm{~b}$ & $8,5 \mathrm{~d}$ & $10 \mathrm{~b}$ & $13 \mathrm{c}$ & $14 \mathrm{c}$ & $15 \mathrm{~b}$ & $16 \mathrm{~b}$ \\
\hline 16 & $\mathrm{~F}_{15}$ & $9 \mathrm{~b}$ & $14 \mathrm{~b}$ & $16 \mathrm{~b}$ & $23 \mathrm{~b}$ & $27 \mathrm{~b}$ & $31 \mathrm{a}$ & $37 \mathrm{a}$ \\
\hline & Jumlah & 137,5 & 178,5 & 224,5 & 294 & 344 & 382,5 & 423 \\
\hline
\end{tabular}

Keterangan: Angka rata rata pada setiap kolom yang diikuti huruf yang sama tidak berbeda nyata menurut uji scott-knot taraf $5 \%$.

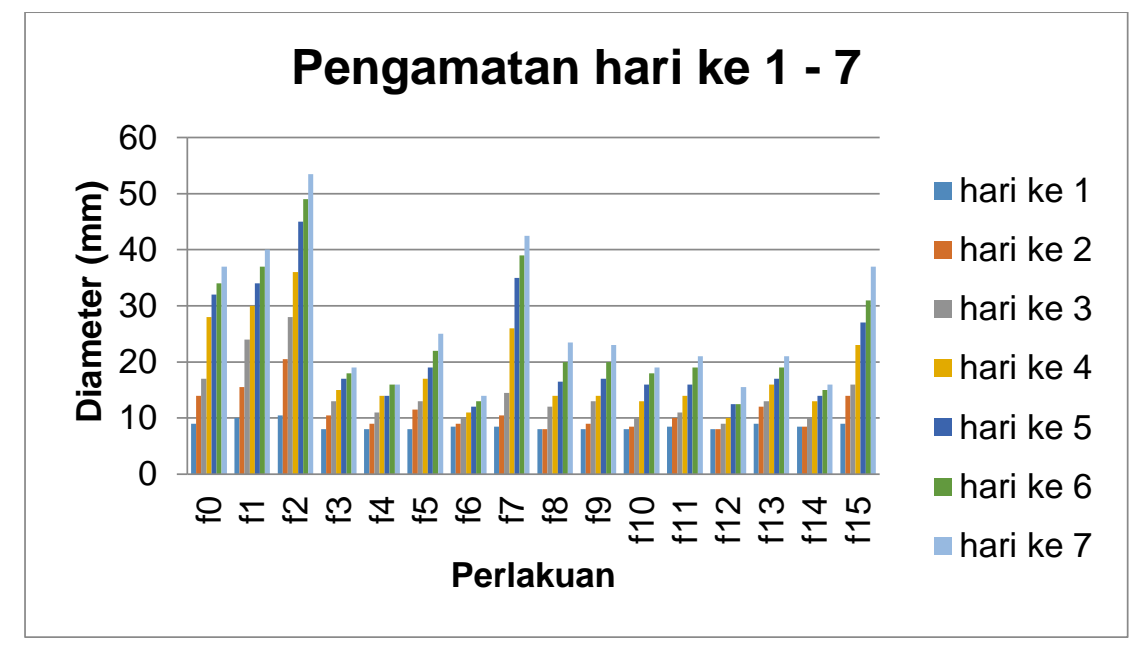

Gambar 1. Grafik Pertumbuhan JamurF. oxysporum 


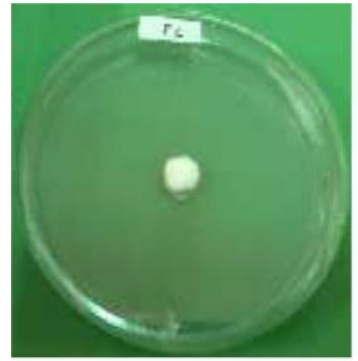

F6

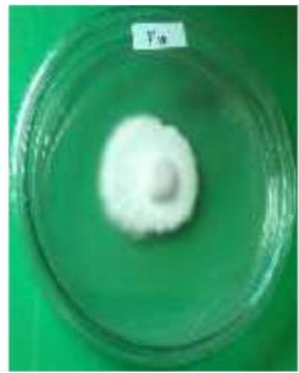

F15

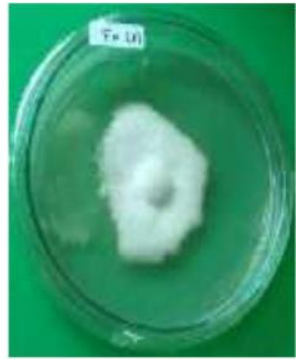

F0

Gambar 2.Hasil Uji Daya Hambat Ekstrak Bawang Putih (f6), fungisida sintetis (f15)dan tanpa perlakuan (f0) TerhadapJamur F. oxysporumpada hari ke 7

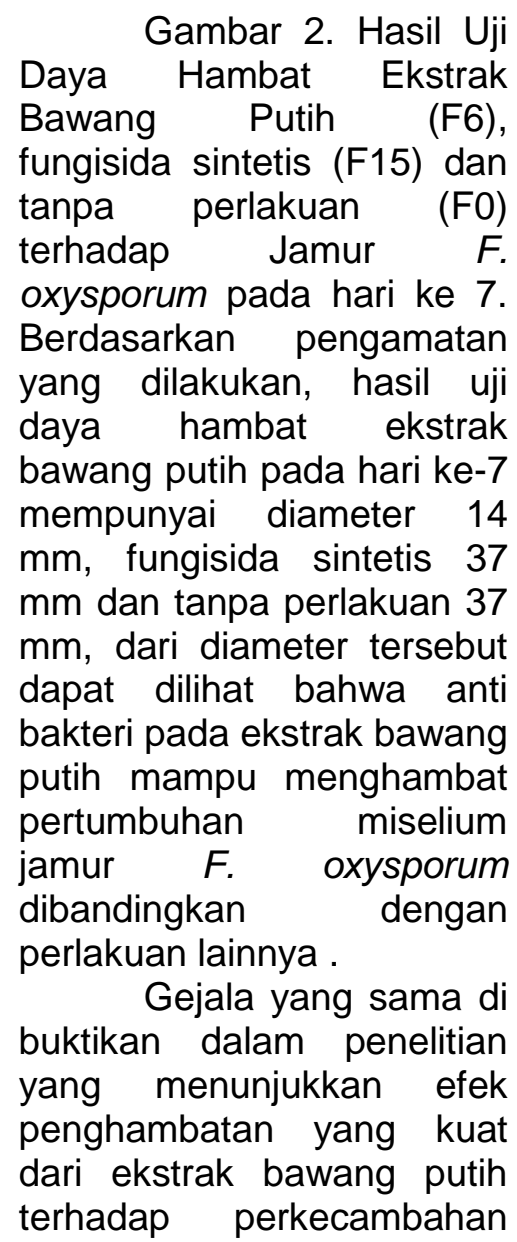

zoospora Phytophthora capsicisebesar 97, 13\% (Zhihui dan Zu li, 2009). Penghambatan pembentukan spora merupakan salah satu mekanisme penghambatan pertumbuhan jamur (Suprapta dkk., 2006). Spora pada jamur berfungsi sebagai alat perkembangbiakan.

\section{Perkecambahan}

spora berhubungan erat dengan kelembaban, suhu yang dapat mempengaruhi banyaknya spora berkecambah.

\section{KESIMPULAN}

1. Fungisida alami berpengaruh nyata dalam menghambat pertumbuhan jamur $F$. Oxysporum.

2. Ekstrak bawang putih konsentrasi $10 \%$ efektif 
menghambat pertumbuhan jamur F. Oxysporum.

\section{DAFTAR PUSTAKA}

Kementrian Pertanian. 2014. Outlook Komoditi Tomat. Pusat Data Dan Sistem Informasi Pertanian Sekretariat Jenderal Kementerian Pertanian.

Martoredjo, T. 1989.Pengantar IImu Penyakit Tumbuhan Bagian dariPerlindungan Tanaman. Andi offset, Yogyakarta.

Mustika, I. dan A.S. Rahmat. 1993. Efikasi Beberapa Macam Produk Cengkehdan Tanaman Lain terhadap Nematoda Lada. Prosiding Seminar HasilPenelitian dalam Rangka Pemanfaatan Pestisida. Bogor.

Suprapta, D. N., M. Subrata, K. Siadi, I.G.A. Rai, F. Tunnisa, and K. Ohsawa. 2006. Fungicidal Activity of Exstract of Several Piperaceae Plant againtsFusarium

oxysporium f.sp. vanillae. Academic Frontier Research Centre.Tokyo University of Agriculture.

Zhihui C. dan $\mathrm{Zu} \mathrm{Li}$. 2009.Allium sativum Extract as a Biopesticide Affecting PepperBlight. International Journal of Vegetable Science, 15:13-23 